\title{
En las ciudades de Ipazia y Tamara: algunas consideraciones sobre las imágenes visuales y las palabras*
}

\author{
Irene María ARTIGAS ALBARELLI \\ Universidad Nacional Autónoma de México
}

La relación que existe entre las palabras y las imágenes visuales, para representar, significar y comunicar, refleja las relaciones que suponemos entre los signos y sus significados, entre los sistemas de representación y el mundo. Normalmente, según W. J. T. Mitchell, en Iconology, Image, Text, Ideology, ${ }^{1}$ suponemos que entre las palabras y las imágenes visuales existe el mismo abismo que entre las palabras y las cosas,

[...] entre (en el sentido más amplio) cultura y naturaleza. La imagen visual es el signo que pretende no ser un signo, enmascarándose como (o para el que cree en ella, obteniendo) proximidad y presencia naturales. La palabra es su "otro", es producción arbitraria y artificial de la voluntad humana que desorganiza la presencia natural al introducir elementos no-naturales en el mundo - tiempo, conciencia, historia y la intervención enajenante de la mediación simbólica. ${ }^{2}$

Así tenemos a la imagen visual, natural y mimética que se asemeja 0 "captura" lo que representa y también la palabra que es un significante arbitrario. Sin embargo, aunque ésta es la forma más común de comprender a las imágenes visuales y a las palabras, otras tradiciones les atribuyeron las cualidades contrarias. De esta forma se habló de la imagen visual, artificial y expresiva que no se asemeja a lo que representa porque esto sólo puede ser representado, o descrito, con palabras y de la palabra que es una imagen natural de lo que significa (por ejemplo, la onomatopeya). Intentemos dar

* Una versión de este trabajo fue presentado en el coloquio "Lengua, literatura y representaciones sociales", en la Unidad de Seminarios "Dr. Ignacio Chávez", UNAM. 9 y 13 de noviembre de 1995.

I W. J. T. Mitchell, Iconology. Image, Text, Ideology. El argumento general de este ensayo está tomado de este libro. Las traducciones de las citas al mismo son mias.

2 Ibid., p. 43. 
ejemplos de estas tradiciones que parecen opuestas y veamos si realmente el abismo al que me referí anteriormente como existente entre las palabras y las imágenes visuales es tan inmenso.

\section{Ciudades de signos. En la ciudad de Ipazia}

De todos los cambios de lengua que debe enfrentar el viajero en tierras lejanas, ninguno igual al que le espera en la ciudad de Ipazia, porque no se refiere a las palabras sino a las cosas. Entré en Ipazia una mañana, un jardín de magnolias se espejaba en lagunas azules, yo andaba entre los setos seguro de descubrir unas damas bellas y jóvenes bañándose; pero en el fondo del agua los cangrejos mordian los ojos de las suicidas con una piedra sujeta al cuello y los cabellos verdes de algas. ${ }^{3}$

Para Jean-Joseph Goux ${ }^{4}$ la historia de la pintura está marcada por rupturas radicales. Tales rupturas han supuesto el cambio de actitud del sujeto que contempla las obras; así, con la aparición de la perspectiva, se pasó de un sujeto frontal a uno focal, y con la aparición del arte abstracto se pasó de un sujeto focal a uno operativo. No vamos a detenernos mucho más en dichas rupturas, pero debemos considerar que para Goux el arte abstracto supuso la "desemantización de lo percibido". El Grupo $\mu$, en su Traité $d u$ signe visuel. Pour une rhétorique de l'image, encuentra que esta suposición, lo mismo que conceptos como "mensaje sin código" de Umberto Eco, "signos no miméticos" de Meyer Shapiro o "expresión del sentido sin referentes" de Louis Marin, son demasiado ideológicos porque suponen que lo icónico o figurativo es la norma y que lo plástico o abstracto, la desviación. Veamos las razones por las cuales esta ideología, que da supremacía a lo icónico, tiene tanta fuerza.

Comencemos por la primera ruptura marcada por Goux: la invención de "un sistema de perspectiva enfocado y completo, con una disminución regular y matemática hacia un punto de fuga fijo". ${ }^{6}$ Con este sistema, inventado por Brunelleschi y sistematizado por Alberti, se podía representar el espacio en una tabla, un papel o un lienzo. Se trataba de una solución "hecha

${ }^{3}$ Italo Calvino, Las ciudades invisibles, p. 61.

${ }^{4}$ Resumido por Groupe $\mu$, Traité du signe visuel. Pour une rhétorique de l'image, p. 22.

${ }^{5}$ Groupe $\mu$, op. cit.

"Rosa Maria LetTS, Introducción a la historia del arte. El Renacimiento, p. 43. 
por el hombre que ilustraba desde el punto de vista humano un mundo natural, del cual la persona es 'centro y medida'. La perspectiva de un punto se llama también perspectiva artificial, porque fue creada por la mente humana". ${ }^{7}$ Es importante resaltar que la perspectiva es una forma de organización y representación icónica del espacio, que supone un punto de vista único para el espectador, por lo que no representa objetivamente el espacio físico. Es fácil observar que dicho punto de vista único no es, como dice Román Gubern, "ajeno al tema del poder político. Así Petitot, en su Raisonnement sur la perspective (1758), recomienda construir los decorados teatrales ubicando su punto de vista en el palco del príncipe, de modo que la máxima jerarquía política goce de la máxima ilusión realista, que decrecerá en cambio para los espectadores, tanto más cuanto más se alejen del príncipe". 9

Sin embargo, olvidando su calificativo de "artificial", la perspectiva se presentó a sí misma como un método infalible de representación, basado en leyes de la óptica y las matemáticas; se supuso, según W. J. T. Mitchell, un sistema de producción mecánica y automática de las verdades de los mundos materiales y mentales:

El mejor indicador de la hegemonía de la perspectiva artificial es la forma en la que niega su propia "artificialidad" y se nombra a sí misma una representación "natural" de la "forma en la que las cosas se ven", de "la forma en que vemos" o [...] de la "forma en la que las cosas son". La perspectiva artificial, ayudada por el ascenso político y económico de Europa occidental, conquistó el mundo de la representación bajo el estandarte de la razón, la ciencia y la objetividad. Ninguna otra contrademostración artística respecto a que existen otras formas de representar lo que "vemos en realidad" ha conseguido resquebrajar la convicción de que estas pinturas (pictures) poseen cierto tipo de identidad con la visión humana y el espacio externo objetivo. La invención de una máquina (la cámara), construida para producir imágenes de este tipo, irónicamente sólo ha reforzado la convicción de que éste es el modo natural de representación. ${ }^{10}$

7 Ibid., p. 44.

${ }^{8}$ Román GUBERN, La mirada opulenta. Exploración de la iconósfera contemporánea.

9 Jbid., p. 80.

${ }^{10}$ W. J. T. MitcheLl, op. cit., p. 37. 
En su libro Mímesis: las imágenes y las cosas, "Bozal explica cómo para Leonardo la pintura ponía a las cosas en presencia del espectador, "conmoviendo sus sentidos con mayor presteza que la poesía [...] el horizonte en que la imagen es posible y, a su vez, que es específico de la imagen, [es un nivel] en el que ella es creadora, no actividad secundaria, ilustración o expresión de una idea anterior ya hecha y bien definida". ${ }^{12}$ El mismo Leonardo compara a la pintura con la poesia, diciendo que la pintura presenta "en un instante la esencia de su objeto en la facultad visual", mientras que la poesía transmite "a la sensibilidad la representación de las cosas nombradas". ${ }^{3}$ Presentación contra representación: olvidar que la perspectiva de un cuadro es una forma de representación del espacio; olvidar también que detrás de dicho sistema de representación hay convenciones. Cuando éstas se disimulan y se hacen invisibles, los espectadores piensan que el arte es exactamente análogo a la realidad.

Bozal encuentra un problema en la postura de Leonardo porque, para él, el poeta también construye imágenes "no menos inmediatas, presentes y evidentes" 14 que las de la pintura: cae en la trampa que supone que ambos medios de representación son análogos a la realidad y olvida que sólo son una forma de representación de dicha realidad. Intentemos, siguiendo el razonamiento de W. J. T. Mitchell, explicar por qué Bozal piensa que salva el honor de la poesía cuando supone que detrás de ella hay imágenes y por qué supone que estas últimas se encuentran más cercanas a la realidad.

En primer lugar, Mitchell se refiere a la utilización del término "imagen" para designar a fotografias, estatuas, ilusiones opticas, mapas, diagramas, sueños, alucinaciones, exposiciones, proyecciones, poemas, recuerdos y hasta ideas. Partamos, como hace él, de la noción de que pareciera ser que la palabra "imagen" se utiliza en su sentido más literal cuando designa a fotografías, estatuas o ilusiones ópticas y que el término se utiliza para designar a las imágenes verbales y mentales de una manera un tanto "metafórica". A continuación, Mitchell expone su idea de que, aunque parezca que las imágenes ópticas y gráficas son más estables que las verbales o perceptuales, no son ni estables, ni estáticas, ni permanentes: "no todos los espectadores, al igual que a las imágenes de los sueños, las perciben de la misma manera; además, no se trata de imágenes exclusivamente visuales ya que su percepción incluye interpretación y aprehensión multisensorial". ${ }^{15}$

\footnotetext{
1 Valeriano Bozal, Mimesis: las imágenes y las cosas.

12 Jbid., p. 112.

${ }^{13} \mathrm{Idem}$.

${ }^{14}$ Idem.

is W. J. T. MitchelL, op. cit., p. 17.
} 
La razón por la cual este tipo de imágenes nos parecen más estables es porque, para explicar la forma en que percibimos, tanto al lenguaje como a la "realidad", hemos utilizado modelos que suponen la formación de las mismas. Recordemos los diagramas en los que se pinta una cabeza viendo una vela, con una imagen de la vela dentro. Todos estos modelos suponen a la conciencia como una actividad de producción, reproducción y representación pictóricas, gobernada por mecanismos parecidos a los de lentes o superficies en las cuales se pueden dejar impresiones o huellas. Sin embargo, prosigue Mitchell:

Ninguna regla exige que la mente se represente a si misma como una figura, o que tenga que ver figuras dentro de sí, como ninguna regla exige que entremos a una galeria o que, una vez dentro, observemos los cuadros que haya ahí. Si elimináramos la noción de que existe algo necesario, natural y automático respecto a la formación de imágenes materiales y mentales, $[. .$.$] podríamos perfectamente reempla-$ zar todo proceso de formación de imágenes por un proceso de observar un objeto o una pintura, dibujo o esbozo; y todo proceso de hablarse a sí mismo por uno de hablarse en voz alta o escribiendo; este reemplazamiento podría ( $y$ de hecho lo hace) moverse en dirección contraria. Podríamos reemplazar lo que llamamos "manipulación física de signos" (pintar, escribir, hablar) por locuciones como "pensar en papel, en voz alta, en imágenes, etcétera". ${ }^{16}$

Sin embargo, la noción de que existen imágenes detrás de las palabras tuvo gran auge, sobre todo durante los siglos XVII y XVIII. Así, por ejemplo, para Joseph Trapp, "las ideas son las imágenes de las cosas, como las palabras lo son de las ideas", ${ }^{17}$ y para Addison, la imagen verbal no era un concepto metafórico ni un término para designar metáforas, figuras y otros ornamentos del lenguaje ordinario. La imagen verbal es "la clave de todo lenguaje". ${ }^{18}$ Este punto de vista que entendía a la poesía, y al lenguaje en general, como un proceso de producción y reproducción pictórica, se vio acompañado por un cierto desprestigio de las figuras retóricas. La noción de "imagen" reemplazó a la de "figura", que fue considerada como un ornamento, pasado de moda, del lenguaje. Las figuras retóricas dejaron de ser instrumentos de conocimiento y se volvieron, por el contrario, obstáculos para el mismo, elementos que a toda costa debían evitarse. Esta idea llevó,

\footnotetext{
Its Ibid., pp. 18-19.

17 Joseph TraPP, cit. por W. J. T. MITChELL, op. cit., p. 19.

18 W. J. T. MiTChell, op. cit., p. 23.
} 
como escribe Steiner en su libro The Colors of Rethoric. Problems in the Relation between Modern Literature and Painting, 19 a "la creencia en la pureza arcaica del lenguaje en la que las palabras y las cosas se encontraban intimamente conectadas, y en la necesidad de recuperar dicha pureza simplificando, eliminando, los meros ornamentos para conseguir 'sencillez matemática'. De ahí el nombre que se le dio a la nueva prosa: 'Estilo directo'". ${ }^{20}$

Se buscó un lenguaje que capturara, contuviera, expresara, organizara, que incluso reemplazara, el mundo. ${ }^{21} \mathrm{Si}$ las imágenes pictóricas son capaces, según la noción de Leonardo, de presentarlo, y detrás de cada palabra existe una imagen, entonces el lenguaje sería capaz de, en vez de sólo representar, de presentar a ese mundo.

De esta forma, los filósofos ilustrados intentaron imitar el poder que suponían el "lenguaje de Adán" tenía: el poder de dar a las cosas "sus nombres reales, ya que él [Adán] tenía la capacidad de ver las esencias en sí mismas y leer las formas sin ningún comentario de sus propiedades respectivas". ${ }^{22}$ Esta idea, continúa Steiner, puede verse en el mismo Bacon cuando se refiere a los ideogramas chinos, a los que considera caracteres reales que expresan cosas o ideas, y no meras letras o palabras.

En el Romanticismo, al hablar del "misterioso proceso de la imaginación", la imagen gráfica o pictórica pasó a un segundo plano, detrás de una imagen "superior", interna, orgánica y viva. Esta imagen, más abstracta y sublime, desplazaría e incluiría la noción empiricista de la imagen verbal como una clara representación de la realidad material. Este proceso llega hasta nuestro siglo y se manifiesta en las ideas imaginistas. Una vez más citemos directamente a Mitchell:

Esta progresiva sublimación de la imagen alcanza su culminación lógica cuando el poema o texto completo es considerado como una imagen o "icono verbal" y cuando esta imagen queda definida no como una semejanza o impresión pictóricas, sino como una estructura sincrónica en cierto espacio metafórico - como aquello que (utilizando las palabras de Pound) "presenta un complejo intelectual y emocional en un instante de tiempo". El énfasis imagista en la utilización de descripciones concretas y particulares en su poesía es, por

${ }^{19} \mathrm{~W}$. STEINER, The Colors of Rethoric Problems in the Relation between Modern Literature and Painting.

${ }^{20} \mathrm{Jbid}$., p. 98.

${ }^{21}$ Ibid., p. 97.

${ }^{22}$ Ibid., pp. 98-99. En este caso, Steiner cita a G. A. Padley y su libro Gramatical Theory in Western Europe, 1500-1700: The Latin Tradition, p. 140. 
sí mismo, un residuo de la noción del siglo XVIII [...] respecto a que la poesia lucha por obtener mayor intensidad y proximidad que las de las imágenes que fluyen de los mismos objetos [...] Sin embargo, lo que distingue el énfasis modernista es la imagen como una especie de estructura cristalina, un modelo dinámico de energía emocional e intelectual corporizado gracias al poema. ${ }^{23}$

El poema "The Red Wheelbarrow" de William Carlos Williams es un buen ejemplo de esta consideración que supone que un poema debia ser una imagen o icono verbal:

so much depends

upon

a red wheel

barrow

glazed with rain

water

beside the white

chickens. ${ }^{24}$

Cada palabra de este poema tiene una función evocativa. Se centra en el objeto - la carretilla roja-y las relaciones esenciales que éste tiene con sus alrededores inmediatos -el agua de la lluvia, los pollos y el poeta. "Las palabras son hechos, equivalentes lingüísticos directos del objeto visual que se examina". ${ }^{25}$ El objeto sigue siendo autónomo, y el hecho de que su existencia en el mundo objetivo sea exactamente la misma que la descrita en el poema constituye una afirmación y un comentario sobre dicho mundo objetivo. El significado del poema reside en una imagen sencilla que ha dejado de ser sólo el tema del mismo y se ha convertido en un objeto del mundo.

Sin embargo, Williams no creyó que la capacidad de la poesía para presentar objetos fuera la misma que la de la pintura, como puede verse en uno de sus últimos poemas, llamado "Still Lifes":26

${ }^{23}$ W. J. T. MITCHELL, op. cil., p. 25.

24 William Carlos Williams, cit. por Bram DiJkstra, Cubism, Stieglitz, and the Early Poetry of William Carlos Williams. The Hieroglyphics of a New Speech, pp. 167-168.

${ }^{25}$ B. DijKstra, op. cit., p. 168.

${ }^{26}$ W. C. Williams, cit. por B. Dijkstra, op. cit., p. 197. 


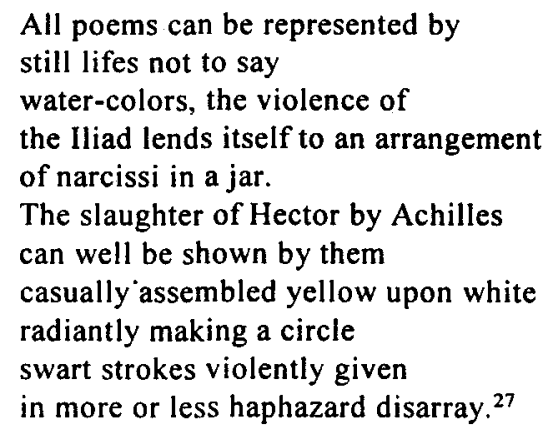

Aquí, Williams expone cómo cualquier buena pintura puede expresar la muerte de Héctor a manos de Aquiles de una forma tan exacta, y mucho más sencilla, a como lo hace Homero en la Iliada, uno de los grandes poemas de la civilización occidental. Williams, como Leonardo, considera que el lenguaje verbal tiene muchas limitaciones si se le compara a las posibilidades de la imagen pictórica: "Pensaba que si sólo pudiera tener éxito en aproximarse a la concentración de aseveraciones que se encuentran en la acuarela más sencilla podría convertir a las palabras en objetos visuales, en aquellos jeroglíficos de un nuevo idioma que él consideraba más poderoso, mucho más intenso, que cualquier otro lenguaje existente". ${ }^{28}$

Para Williams, un poema debía evocar una imagen, sin embargo no creyó que ésta pudiera ser tan precisa ni detallada como las imágenes de una pintura.

Recordemos el epígrafe a esta sección. En la ciudad de Ipazia, cada vez que el viajero intenta buscar algo, siguiendo la lógica de su propio lenguaje, encuentra otra cosa. Tiene que olvidarse de él para así liberarse "de las imágenes que hasta entonces me habian anunciado las cosas que buscaba" 29 para así entender el lenguaje de la ciudad. Así, aprende que, para que "lo asalte el ansia amorosa" que buscaba antes en las "lagunas azules", ahora tiene que ir a las caballerizas y picaderos "para ver a las hermosas mujeres que montan a caballo"; ${ }^{30}$ aprende que para encontrar "el alimento y estímulo de la música" 31 tiene que ir a los cementerios, en donde "de una fosa a la

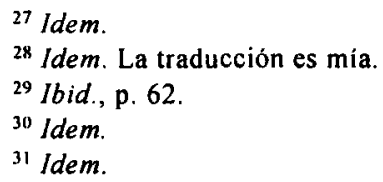


otra se responden trinos de flautas, acordes de arpas". ${ }^{32}$ El único problema es que cuando quiera dejar la ciudad, recordemos que Marco Polo es el que cuenta la historia y seguramente querrá seguir viajando: "Sé que no tendré que bajar al puerto sino subir al pináculo más alto de la fortaleza y esperar que pase una nave por allá arriba. ¿Pero pasará alguna vez? No hay lenguaje sin engaño". ${ }^{33}$ Hasta la lengua de Ipazia, que se refiere directamente a las cosas y nos hace pensar en esta necesidad de igualar a las palabras con los objetos que nombran, es un engaño, una construcción, algo diferente a las mismas cosas.

\section{En la ciudad de Tamara}

[En Tamara] El ojo no ve cosas sino figuras de cosas que significan otras cosas: las tenazas indican la casa del sacamuelas, el jarro la taberna, las alabardas, el cuerpo de guardia, la balanza el herborista. Estatuas y escudos representan leones delfines torres estrellas: signo de que algo -quién sabe qué- tiene por signo un león o delfin o torre o estrella [...] La mirada recorre las calles como páginas escritas: la ciudad dice todo lo que debes pensar, te hace repetir su discurso, y mientras crees que visitas Tamara, no haces sino registrar los nombres con los cuales se define a sí misma y a todas su partes. ${ }^{34}$

Hasta aquí supusimos, como muchos, incluido el mismo Williams, que el sentido literal de la palabra "imagen" es el de una representación pictórica, gráfica; se le consideró como un objeto material y concreto, al cual se oponían extensiones figurativas como las nociones de imagineria mental, verbal o perceptual. Sin embargo, apunta Mitchell, ésa es sólo una manera de comprender el significado del término "imagen". Existe otra tradición que consideró que el sentido "literal" del término no era pictórico, que incluso era antipictórico. El crítico se refiere a esta tradición de la siguiente forma:

Se trata de la tradición que comienza, por supuesto, con el relato de la creación del hombre "a imagen y semejanza" de Dios. Las palabras que ahora traducimos como imagen (el hebreo tselem, el griego eikon y el latín imago) son comprendidas correctamente cuando, como

\footnotetext{
32 Idem.

${ }^{33}$ 1. Calvino, op. cit., p. 62.

${ }^{34}$ Ibid., pp. 28-29.
} 
los comentaristas insisten, se les considera una "semejanza" espiritual, general y abstracta y no una figura material. La normal adición después de "imagen" de la frase "y semejanza" (demuth en hebreo, homoioos en griego, y similute en latín) no debe comprenderse como si se tratara de dar más información sino como intentando evitar una posible confusión: "imagen" debe comprenderse no como "figura", sino como "semejanza", como similitud espiritual. ${ }^{35}$

Mitchell no se extraña de que una tradición obsesionada por los tabúes contra las imágenes talladas y la idolatría quisiera acentuar un sentido espiritual e inmaterial de la noción de imagen. La imagen como semejanza incluye una afirmación de la diferencia. Así, tomando su ejemplo, cuando decimos que un árbol es como otro, no suponemos que sea idéntico a otro árbol, sino que ambos se parecen en algunos aspectos y en otros no. Sin embargo, el que se asemejen no quiere decir que uno sea la imagen de otro. La palabra "imagen" sólo aparece cuando intentamos explicar cómo percibimos las similitudes, cuando construimos una teoría de nuestra forma de percibir. La explicación inmediatamente se refiere a cierto tipo de intermediario u objeto trascendental —una idea, forma o imagen mental- que proporciona un mecanismo que se refiera a la manera en que formamos categorías. Sin embargo, continúa Mitchell, estos objetos transcendentales no necesariamente tienen que ser comprendidos como figuras o impresiones. Pueden ser listas de predicados que enumeren las características de una clase de objetos. En el caso del árbol pudieran ser: objeto vertical, alto; con follaje verde, arriba; y raíces, en el suelo. No necesariamente tenemos que pensar en una figura para comprender esta serie de predicados, aunque normalmente lo hagamos. En pocas palabras, la imagen como semejanza puede ser comprendida como una serie de predicados que listan similitudes y diferencias. ${ }^{36}$ Pero, ¿cuáles fueron las razones por las cuales a este concepto de semejanza espiritual se le asignó la palabra "imagen", confundida con el concepto de representación pictórica? Mitchell contesta:

Con seguridad, este uso no se fomentó siguiendo los intereses de los enemigos de la idolatría; sólo se puede conjeturar que la terminología de la imagen fue el resultado de una especie de "desplazamiento" metafórico, de la búsqueda de una analogía concreta que se hizo literal bajo las presiones de tendencias idólatras entre pueblos cercanos y entre los mismos israelitas. La confusión entre semejanza y figura

${ }^{35}$ W. J. T. MitChelL, op. cit., p. 31.

36 Jbid., p. 33. 
pudo haber sido útil para un sacerdocio a cargo de la educación de congregaciones iletradas. El sacerdote sabría que la "imagen verdadera" no era un objeto material sino que se encuentra incluida en una comprensión espiritual -esto es, verbal y textual-; sin embargo, si a la gente se le explicaba como una imagen externa, sus sentidos se verían gratificados y su devoción aumentaría. La distinción entre la imagen espiritual y material, interna y externa, no fue sólo materia para la doctrina teológica, sino que también lo fue para la política, desde la preservación del poder de las castas de sacerdotes, hasta la lucha entre los movimientos conservadores y de reforma (iconófilos e iconoclastas), pasando por la preservación de la identidad nacional (esto es la lucha israelita por liberarse de la idolatría). ${ }^{37}$

Si sumamos a esto el efecto de la invención de la perspectiva, comprenderemos la razón por la cual suponemos al sentido literal de la palabra imagen como el de una representación pictórica o gráfica.

Sin embargo, la noción de imagen como "semejanza espiritual" permaneció de manera subterránea. Recordemos cómo los pintores siempre se vanagloriaron, bajo términos como "expresión", de pintar más de lo que "únicamente el ojo podía ver". La iluminación dramática de la tradición veneciana renacentista utilizaba "colores ricos y pinceladas personales, a veces apasionadas [... De ellas] se derivan pintores tales como El Greco y Rembrandt". ${ }^{38}$ Las cualidades emocionales del trabajo de Rubens, la expresividad de Goya o Delacroix, y la obra de Blake o Turner son trabajos de "introspección" en los que se pueden observar elementos que no sólo "podían ser vistos con el ojo" y copiados. De esta misma forma, los pintores simbolistas franceses manipularon el color de sus cuadros para expresar el estado de ánimo que evocaban los objetos que percibian y no el aspecto que tenían; así también, las imágenes alucinantes de Munch dieron forma pública a sus angustias personales. La expresión en dichas obras se refiere a "la colocación artificiosa de ciertas claves en una pintura que nos permiten formular una acto de ventriloquía, un acto que carga a la pintura de elocuencia, elocuencia que es particularmente no visual y verbal". 39

Muchos otros artistas exploraron esta rama expresiva de la pintura. Algunos de ellos son Kokoschka, Derain, Vlaminck, Matisse, Kirchner, Nolde y Kandinsky. En la obra de este último, la representación icónica fue desapareciendo para dar paso a la expresión lírica. En 1910, pensando que los

${ }^{37}$ lbid., p. 35.

${ }^{38}$ Nikos Stangos, comp., Conceptos de arte moderno, p. 30.

${ }^{39}$ W. J. T. MitChelL, op. cit., p. 41. 
colores y las pinceladas eran lo suficientemente comunicativos para depender de un tema, pintó sus famosas acuarelas abstractas. "Aquellas primeras improvisaciones son alegres explosiones de sentido mistico, que encuentran justificación no en un deber cualquiera del artista hacia la sociedad [deber de representar el mundo], sino en lo que se debe a sí mismo, en su necesidad de hacer visible el núcleo de su ser". ${ }^{40}$

En estos trabajos, la imagen "se vuelve totalmente abstracta y ornamental; no representa ninguna figura ni espacio, sino que sólo presenta sus propios elementos formales y materiales". ${ }^{41} \mathrm{La}$ imagen abstracta pareciera, a primera vista, haber escapado del cauce de la representación y la elocuencia verbal, dejando atrás a la mimesis figurativa y a elementos como la narrativa o la alegoría. Sin embargo, una pintura abstracta -que exige al sujeto operativo de Goux -, continúa Mitchell, es

[...] una "palabra pintada", un código pictórico que exige apologias verbales tan elaboradas como las de cualquier modo tradicional de pintura. Las manchas y brochazos de colores sobre el lienzo se vuelven, en el contexto adecuado - esto es, en la presencia del ventrílocuo adecuado- aseveraciones sobre la naturaleza del espacio, la percepción y la representación. ${ }^{42}$

Esto es lo que nos han recordado los pintores de este siglo: la pintura es también un lenguaje, un código. Cuando los pintores cubistas nos recordaron que la pintura es "una clase de lenguaje que se puede manipular para transcribir una realidad en otra de términos completamente diferentes"; cuando los pintores de la escuela expresionista alemana utilizaron el arte para, antes que nada, transmitir sus experiencias personales y, como quería Kandinsky, "vincular la naturaleza plástica del arte directamente con la vida interior del hombre"; 44 cuando los futuristas añadieron a la preocupación cubista de representar un objeto determinado desde diversos puntos de vista, la dimensión temporal; cuando Mondrian desarrolla un estilo "puramente geométrico, carente de toda referencia a la figura o el paisaje, hasta alcanzar el estadio en el que los elementos formales de su pintura se simplificaron al máximo"; 45 cuando hicieron esto, repito, todos ellos nos re-

${ }^{40}$ Edward LUCIE-SMITH, El arte hoy; del expresionismo abstracto al nuevo realismo, p. 40.

${ }^{4}$ W. J. T. MitChELl, op. cit., p. 41.

42 Idem.

${ }^{43}$ E. LUCIE-SMITH, op. cil., p. 26.

44 N. STANGOS, comp., op. cit., p. 39.

${ }^{45}$ E. LUCIE-SMITH, op. cit., p. 36. 
cordaron las convenciones de la perspectiva artificial e impidieron que las volviéramos a olvidar. Todos ellos pintaron lo que la tradición renacentista había hecho invisible. Todos ellos nos obligaron a "prestar nuestra voz" a la pintura.

En conclusión, las imágenes pictóricas se encuentran contaminadas con lenguaje verbal. El ventrílocuo, en palabras de Mitchell, en el que nos convertimos cuando observamos una pintura abstracta siempre estuvo ahi. Un cuadro siempre nos hace articular ideas respecto a él, ya sea haciéndonos producir una secuencia narrativa, ya sea porque funciona alegóricamente y tenemos que "leerlo", o bien sea porque exprese ciertas emociones que tenemos que interpretar. Ahora bien, como el mismo Mitchell nos advierte: "El reconocimiento de que las imágenes pictóricas son inevitablemente convencionales y se encuentran contaminadas por el lenguaje no debe lanzarnos a un abișmo de significantes infinitamente regresivos", ${ }^{46}$ como, ya lo advertía Calvino, ocurría en la ciudad de Tamara, donde el viajero nunca sabrá cómo es verdaderamente la ciudad que visita. Bajo "la apretada envoltura de signos" ${ }^{47}$ el hombre nunca será capaz de verla. Es más, a las afueras de la ciudad "se abre el cielo donde corren las nubes. En la forma que el azar y el viento dan a las nubes el hombre se empeña en reconocer figuras: un velero, una mano, un elefante..." ${ }^{48} \mathrm{En}$ la ciudad, construcción humana, el hombre no ve más que lo que ya conoce, al salir de ella, sigue viendo lo que ya conoce. Nada nuevo le es permitido porque su lenguaje lo lanza, como en "propulsión a chorro", hacia lo mismo.

El reconocimiento de que las imágenes pictóricas se encuentran contaminadas con lenguaje verbal únicamente, volviendo a Mitchell, deben implicar para el estudio del arte que "algo similar a la noción renacentista de $u t$ pictura poesis está siempre con nosotros. La dialéctica entre la palabra y la imagen parece ser una constante en la fábrica de signos que una cultura teje a su alrededor". ${ }^{49}$ Quisiera terminar citando a Calvino y la respuesta que Marco Polo da a Kublai cuando éste le pregunta hacia qué ciudad nos impulsan los vientos propicios, para ejemplificar el rumbo que el estudioso de las relaciones entre las palabras y las imágenes visuales debe seguir, ya que es claro que, aunque debe visitarlas, no puede quedarse únicamente en una de las ciudades a las que me referí anteriormente. Marco contesta a la pregunta del Khan:

${ }^{46}$ W. J. T. MITCHELL, op. cit., p. 43.

47 Jbid., p. 29.

48 Idem.

49 Ibid., p. 43. 
A veces me basta una vista en escorzo que se abre justo en medio de un paisaje incongruente, unas luces que afloran en la niebla, el diálogo de dos transeúntes que se encuentran en pleno trajín, para pensar que a partir de ahí juntaré pedazo por pedazo la ciudad perfecta, hecha de fragmentos mezclados con el resto, de instantes separados por intervalos, de señales que uno envía y no sabe quién recibe. Si te digo que la ciudad a la cual tiende mi viaje es discontinua en el espacio y en el tiempo, a veces rala, a veces densa, no creas que haya que dejar de buscarla. Quizás mientras nosotros estamos hablando está asomando, esparcida dentro de los confines de tu imperio, puedo rastrearla, pero de la manera que te he dicho. ${ }^{50}$

\section{Bibliografía}

Bozal, Valeriano, Mímesis: las imágenes y las cosas. Madrid, Visor, 1987. (Col. La balsa de la Medusa)

CALvINO, Italo, Las ciudades invisibles. Trad. de Aurora BERNÁRDEZ. Madrid, Siruela, 1990.

DiJKSTRA, Bram, Cubism, Stieglitz, and the Early Poetry of William Carlos Williams. The Hieroglyphics of a New Speech. Princeton, Universidad de Princeton, 1969.

Groupe $\mu$, Traité du signe visuel. Pour une rhétorique de l'image. París, Éditions du Seuil, 1992.

GUBERN, Román, La mirada opulenta. Exploración de la iconósfera contemporánea. 3a. ed. Barcelona, Gustavo Gili, 1993.

LETTS, Rosa María, Introducción a la historia del arte. El Renacimiento. Barcelona, Gustavo Gili, 1981.

LUCIE-SMITH, Edward, El arte hoy; del expresionismo abstracto al nuevo realismo. Madrid, Cátedra, 1983.

MitChell, W. J. T., Iconology. Image, Text, Ideology. Chicago/Londres, Universidad de Chicago, 1986.

${ }^{50}$ I. Calvino, op. cit., p. 170. 
PADley, G. A., Gramatical Theory in Western Europe, 1500-1700: The Latin Tradition. Cambridge, Universidad de Cambridge, 1976.

Stangos, Nikos, comp., Conceptos de arte moderno. Versión española de Joaquín SÁNCHEz BlANCO. Madrid, Alianza Editorial, 1986.

STEINER, W., The Colors of Rethoric Problems in the Relation between Modern Literature and Painting. Chicago/Londres, Universidad de Chicago, 1982. 